\section{Determination of plasmatic cortisol for evaluation of animal welfare during slaughter}

\author{
Edmondo Ceci, ${ }^{1}$ Patrizia Marchetti, ${ }^{1}$ \\ Giorgio Samoilis, ${ }^{2}$ Stefano Sportelli, ${ }^{1}$ \\ Rocco Roma, ${ }^{3}$ Roberta Barrasso, ${ }^{1}$ \\ Giuseppina Tantillo, ${ }^{1}$ Giancarlo Bozzo ${ }^{1}$ \\ ${ }^{1}$ Department of Veterinary Medicine, \\ University of Bari Aldo Moro, Bari; \\ ${ }^{2}$ Freelance Veterinarian, Bari; \\ ${ }^{3}$ Department of Agricultural and \\ Environmental Sciences, University of \\ Bari Aldo Moro, Bari, Italy
}

\begin{abstract}
The plasmatic cortisol levels of 60 eight-month-old calves (Charolais breed) were measured as stress indicators resulting from two types of slaughter: traditional and religious rite. The plasmatic cortisol levels were evaluated during three different stages of their productive life: during growth, after transport and during slaughter. The thirty calves slaughtered after stunning showed plasmatic cortisol values of $4.85 \pm 3.2$; $36.36 \pm 12.2$ and $45.08 \pm 14.1 \mathrm{nmol} / \mathrm{L}$, during growth, in the slaughterhouse stables and during exsanguination, respectively. Conversely, the average values found in the thirty calves subjected to ritual slaughter were $2.96 \pm 1.2 ; 31.65 \pm 25.4$ and $68.70 \pm 30.6$ $\mathrm{nmol} / \mathrm{L}$. The results of the study showed that animal welfare should be improved in both forms of slaughter.
\end{abstract}

\section{Introduction}

Cortisol is a life-sustaining hormone produced by the adrenal cortex in response to the pituitary ACTH hormone (Sjaastad, 2013). It is often called as stress hormone because its production increases during severe psychophysical stress conditions and therefore, it represents an indicator of animal welfare (Greenwood and Shutt, 1992; Stewart et al., 2005).

Cortisol detection is used as a physiological indicator in dairy cows, pigs and goats (Greenwood and Shutt, 1992; Cook et al., 1996; Pol et al., 2002) and it is desirable that it may also be applied to beef cattle.

The study, resulting from a partnership between the Food Safety Section of the Department of Veterinary Medicine, Bari University and the Meat Processing Industry, Siciliani S.p.A. in Apulia region (Southern Italy), was conducted in the period between April and June 2017.
Therefore, the aim of the study was to compare concentrations of plasmatic cortisol (detected always at 6:00 a.m. to exclude a circadian variation) in beef cattle, subjected to traditional slaughter (with stunning) and with religious Jewish rite (without stunning), during growth, after transport and during slaughter.

\section{Materials and Methods}

\section{Ethical statement}

The experimental procedures were approved by the ethical committee of the Department of Veterinary Medicine, Bari University (Protocol n.: 605-III/13, 04/04/2017).

\section{Sampling}

The study was carried out on a total of sixty Charolaise male beef cattle of eightmonths of age, raised in a free paddock at a farm located in Taranto and regularly slaughtered, exclusively at Siciliani S.p.A (transport time: about $30 \mathrm{~min}$ ). The sixty animals were divided in two experimental groups; in particular, the first group of HTMLDirectthirty animals was selected from breeding by the responsible Rabbi of the Shechitàh Committee, in charge to verify the whole chain production, in order to ensure a product conforming to Jewish rules. These animals were slaughtered according to religious rite (without stunning). Conversely, the other thirty animals were slaughtered after stunning, by captive bolt gun, as required by EC Regulation 1099/2009 (European Commission, 2009).

The plasmatic cortisol levels were evaluated during three different stages of each animal productive life: i) at a farm, ii) after transport, and iii) during slaughter.

The sampling was carried out in breeding one week before slaughter; in the lairage facilities of the slaughterhouse, thirty minutes after the discharge of the animals at the slaughterhouse; and finally, the third sample was picked up immediately after the bout.

The blood samples collected in breeding and standing stalls were obtained by picking from the jugular vein in a vacutainer containing ethylenediaminotetraceticacid (EDTA). Conversely, the blood samples collected during the slaughter phase were harvested immediately after the exsanguination phase.

Then the samples were stored in ice at $0^{\circ} \mathrm{C}$, avoiding freezing, and then sent to the reference laboratory not later than sixty minutes.
Correspondence: Edmondo Ceci, Department of Veterinary Medicine, University of Bari "Aldo Moro", Strada Prov.le per Casamassima km 3, 70010 Valenzano (BA), Italy.

Tel: +39.080.5443851 - Fax: +39.080.5443851.

E-mail: edmondo.ceci@uniba.it

Key words: Animal welfare; Stress markers; Cortisol.

Conflict of interest: the authors declare no potential conflict of interest.

Received for publication: 14 July 2017. Revision received: 29 August 2017. Accepted for publication: 4 September 2017.

This work is licensed under a Creative Commons Attribution-NonCommercial 4.0 International License (CC BY-NC 4.0).

(C) Copyright E. Ceci et al., 2017

Licensee PAGEPress, Italy

Italian Journal of Food Safety 2017; 6:6912

doi:10.4081/ijfs.2017.6912

\section{Elisa test}

\section{Description}

The cortisol ELISA immunoassay test (Bovine-Cortisol ELISA; My-Bio-Source, San Diego, CA, USA) is designed for the quantitative determination of cortisol in serum/plasma or urine samples. The test is used for the diagnosis and monitoring of physiological/pathological conditions related to serum/plasma cortisol in bovine and related species.

\section{Reagent preparation}

All reagents should be brought to reach room temperature $\left(25-28^{\circ} \mathrm{C}\right)$ before use and all reconstitute tubes may take 30-40 minutes before being completely dissolved. Enzyme conjugate should be stored at $-20^{\circ} \mathrm{C}$ for good stability if not used immediately. Highly concentrated samples should be diluted with sample diluent (e.g. 1:5, or $1: 10)$ to bring to a readable range on the curve.

\section{Assay procedure}

First, set standard wells, sample wells and blank/control wells, add standard $50 \mu \mathrm{L}$ to each standard well, add sample $50 \mu \mathrm{L}$ to each sample well, add sample diluent $50 \mu \mathrm{L}$ to each blank/control well. It is recommended that all standards, samples and sample diluent be added in duplicate to the plate. Second, add $100 \mu \mathrm{L}$ of HRP\% conjugate reagent to each well, cover with a closure plate membrane and incubate for $60 \mathrm{~min}$ utes at $37^{\circ} \mathrm{C}$. Third, wash the plate 4 times with wash solution $(250-300 \mu \mathrm{L})$ per well. Invert plate, tap firmly against absorbent 
paper to remove any residual moisture. Fourth, add $100 \mu \mathrm{L}$ of TMB colour reagent into each well (including the blanks). Fifth, incubate the plate for $30 \mathrm{~min}$ at $18-25^{\circ} \mathrm{C}$ in vortex without shaking. Sixth, stop the reaction by adding $100 \mu \mathrm{L}$ di $\mathrm{H}_{2} \mathrm{SO}_{4} 1 \mathrm{M}$ to each well. Gently, mix for 1-2 minutes. Seventh, determine the optical density (OD) of each well within 5 min., using a micro plate reader set to $450 \mathrm{~nm}$. If wavelength correction is available, set to $540 \mathrm{~nm}$ or $570 \mathrm{~nm}$.

\section{Calculation of results}

Average the duplicate readings for each standard and sample and subtract the average OD of Blank.

Create a standard curve by reducing the data using computer software capable of generating a four parameter logistic (4-PL) curve-fit.

If samples have been diluted, the concentration read from the standard curve must be multiplied by the dilution factor.

\section{Performances}

Sensitivity: the minimum detectable dose of bovine cortisol is typically less than $0.049 \mathrm{ng} / \mathrm{mL}$. Detection range: $0.049-200$ $\mathrm{ng} / \mathrm{mL}$. Specificity: this assay has high sensitivity and excellent specificity for detection of bovine cortisol. No significant crossreactivity or interference between bovine cortisol and analogues was observed. IntraAssay Precision CV (\%) $<8 \%$. Inter-Assay Precision CV $(\%)<10 \%$.

\section{Statistical analysis}

General data analysis have been processed with Excel software: i) univariate, central tendency and concentration; ii) multivariate, using one-way analysis of variance applied to two different sample (traditional and ritual slaughter).

For each group, a box plot has been created showing plasmatic cortisol distribution around the mean value in the three-different step of the production process (cattle farm, in the lairage facilities and during exsanguination stage) (Figure 1).

\section{Results and Discussion}

The bovine group slaughtered with previous stunning by captive bolt gun pointed out an average concentration of plasmatic cortisol in the amount of $4.85 \pm 3.2$; $36.36 \pm 12.2$ e $45.08 \pm 14.1 \mathrm{nmol} / \mathrm{L}$ for each step of the sampling.

Conversely, the group of animals slaughtered by Kosher ritual showed, a lower concentration of cortisol equal to $2.96 \pm 1.2, \quad 31.65 \pm 25.4$, and $68.70 \pm 30.6$ $\mathrm{nmol} / \mathrm{L}$ in the different steps (Table 1).

Moreover, according to the concentration indexes in descriptive analysis (Table 1), a high percentage of data were closer to the mean values (positive kurtosis and low skewness).

ANOVA results showed that the differ- ence between plasmatic cortisol concentration, observed in the two different slaughtered groups, are significant ( $\mathrm{F}$ value higher than 1) only for the farming and exsanguination phase (Table 2).

\section{Conclusions}

The findings of our investigation suggest that both traditional and religious slaughtering have positive and negative aspects. For instance, animals slaughtered by the religious rite appear to have lower cortisol levels during growth and during the handling phase at the slaughterhouse than animals subjected to traditional slaughter. On the other hand, the plasmatic cortisol levels determined immediately after the exsanguination phase seem to be much higher than those observed in animals slaughtered traditionally (Tables 1 and 2; Figure 1).

In agreement with previous studies (Önenç and Kaya, 2004), these findings confirm that the slaughtering method may influence the plasmatic cortisol levels, which play a role in correct acidification of meat.

After animal death by exsanguination, muscles present anoxia conditions, triggering anaerobic glycolysis, and glycogen is hydrolysed to lactic acid. Therefore, meat $\mathrm{pH}$ decreases from 7 to 5.5 , a condition

Table 1. Descriptive statistics.

\begin{tabular}{|c|c|c|c|c|c|c|c|c|c|c|}
\hline & \multicolumn{5}{|c|}{ Central tendency } & \multicolumn{4}{|c|}{ Concentration } \\
\hline & & Average & Average trim 5\% & SD & Median & SEM & Min & Max & Kurtosis & Skewness \\
\hline \multirow{3}{*}{ Total sample } & Cattle farm & 3.91 & 3.61 & 2.60 & 3.29 & 0.34 & 1.50 & 16.19 & 7.45 & 2.18 \\
\hline & Lairage facilities & 34.00 & 32.16 & 19.95 & 31.20 & 2.58 & 5.19 & 156.60 & 24.00 & 4.02 \\
\hline & Exsanguination & 56.89 & 54.00 & 26.48 & 55.09 & 3.42 & 23.47 & 175.00 & 6.69 & 2.03 \\
\hline \multirow[t]{3}{*}{ Religious Jewish Rite } & Cattle farm & 2.96 & 2.87 & 1.21 & 3.00 & 0.22 & 1.50 & 6.60 & 1.31 & 0.96 \\
\hline & Lairage facilities & 31.65 & 28.21 & 25.48 & 28.79 & 4.65 & 5.19 & 156.60 & 21.31 & 4.24 \\
\hline & Exsanguination & 68.70 & 65.91 & 30.61 & 66.95 & 5.59 & 23.47 & 175.00 & 4.59 & 1.74 \\
\hline \multirow{3}{*}{ Traditional slaughter } & Cattle farm & 4.85 & 4.52 & 3.23 & 4.49 & 0.59 & 1.50 & 16.19 & 3.91 & 1.53 \\
\hline & Lairage facilities & 36.36 & 35.97 & 12.21 & 34.40 & 2.23 & 18.40 & 62.60 & -0.75 & 0.52 \\
\hline & Exsanguination & 45.08 & 44.50 & 14.15 & 42.70 & 2.58 & 23.70 & 79.90 & -0.33 & 0.51 \\
\hline
\end{tabular}

SD, standard deviation; SEM, standard error of mean.

Table 2. Analysis of variance.

\begin{tabular}{|c|c|c|c|c|c|c|}
\hline & & Sum of squares & Df & Average of squares & Fisher's F & $\mathbf{P}$ \\
\hline Cattle farm & $\begin{array}{l}\text { Between groups } \\
\text { Within the groups } \\
\text { Total }\end{array}$ & $\begin{array}{c}53.26 \\
345.09 \\
398.35\end{array}$ & $\begin{array}{c}1 \\
58 \\
59\end{array}$ & $\begin{array}{c}53.26 \\
5.95\end{array}$ & 8.952 & 0.004 \\
\hline Lairage facilities & $\begin{array}{l}\text { Between groups } \\
\text { Within the groups } \\
\text { Total }\end{array}$ & $\begin{array}{c}333.80 \\
23154.21 \\
23488.01\end{array}$ & $\begin{array}{c}1 \\
58 \\
59\end{array}$ & $\begin{array}{l}333.80 \\
399.21\end{array}$ & 0.836 & 0.364 \\
\hline Exsanguination & $\begin{array}{l}\text { Between groups } \\
\text { Within the groups } \\
\text { Total }\end{array}$ & $\begin{array}{c}8370.46 \\
32988.53 \\
41358.99\end{array}$ & $\begin{array}{c}1 \\
58 \\
59\end{array}$ & $\begin{array}{c}8370.46 \\
568.77\end{array}$ & 14.717 & 0.000 \\
\hline
\end{tabular}

Df, degree of freedom. 
essential for reduction of bacterial growth, as indicated in the guidelines of the European Community (Regulation EC 853/2004; European Commission, 2004).

These findings mirror the results of previous studies (Cenci-Goga and Fermani, 2010 and Cenci-Goga et al. (2010), and show that it is possible to reduce the glycogen levels by safeguarding the animal welfare conditions in the days before slaughtering, during transportation and exsanguination.

Therefore, in order to avoid adverse effects on the carcass due to $\mathrm{pH}$ values higher than 5.5 (such as decreased shelf life, color alterations and decreased tenderness), the concentration of plasmatic cortisol should be assessed carefully both in the management of animal welfare during growth, and shortly before the slaughtering phases (Informatore Zootecnico, 2009).

The post-slaughtering kosher process requires treatment of the carcasses in saline solution. This process is necessary to remove blood from the muscle tissues, but it may affect negatively the color, flavor and organoleptic quality of meat. In addition, this procedure may alter the oxidative processes (Farouk et al., 2014).

Cortisol influences the processes of degradation of proteins and fats and increased levels of cortisol, even in the late slaughtering phases, may alter the organoleptic characteristics of meat. A considerable decrease in marbling fat affects negatively meat flavor and tenderness.

Also, the results of this survey suggest that standardisation of the procedures for animal handling and containment at the slaughterhouse may be achieved by training of workers to manage correctly the various steps of the procedure. This is necessary to reach high hygiene and organoleptic stan-
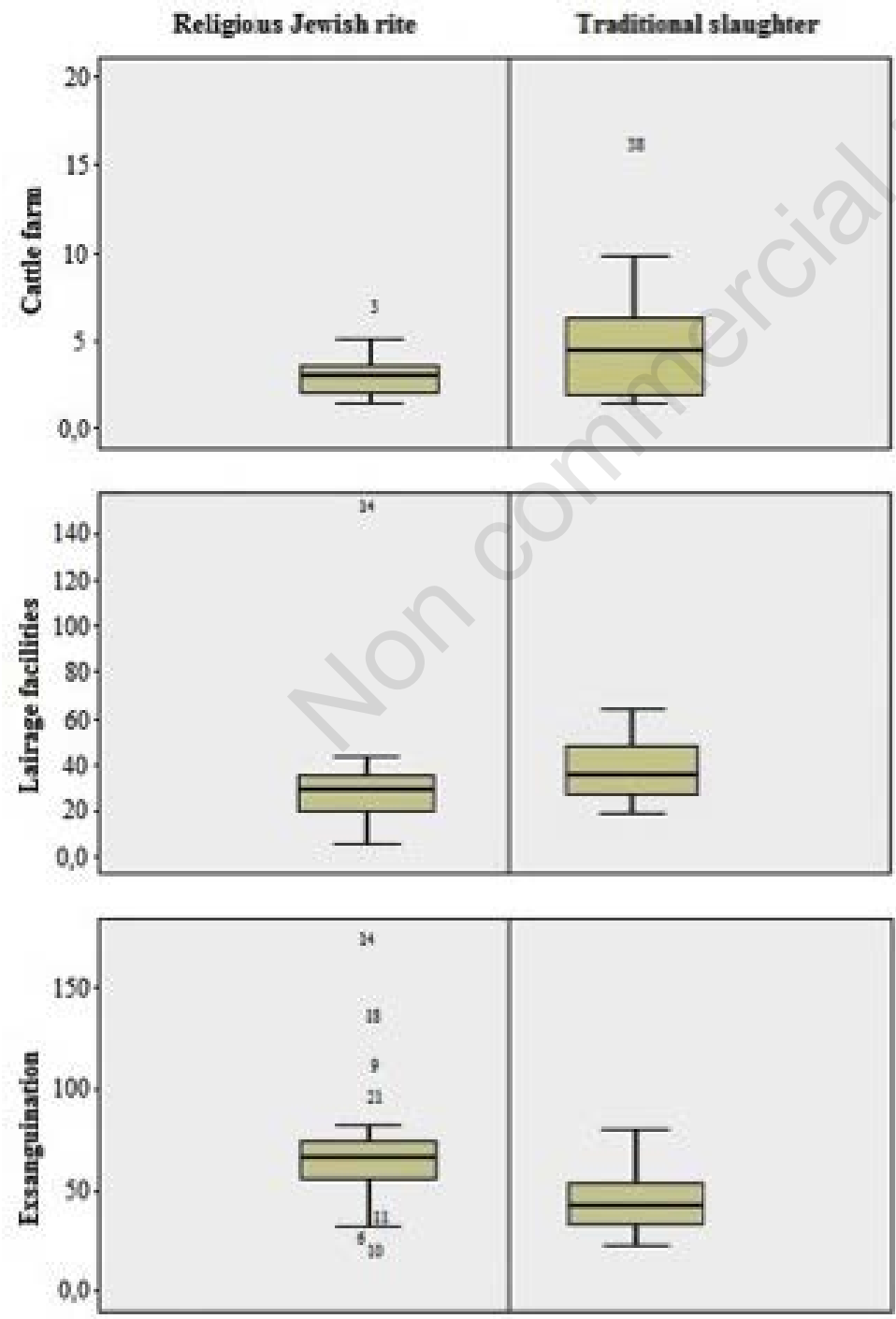

Figure 1. Distribution of plasmatic cortisol concentrations.

dards of meat (Bozzo et al., 2017). For this purpose, non-coercive and non-aggressive attitude of farm and slaughterhouse operators is essential (Lensink et al., 2001; Faucitano, 1998).

Animal welfare is pivotal to guarantee hygiene and quality of productions. In 2009-2010, the European Economic and Social Committee (EESC) released comments on animal welfare labeling, introducing the possibility to use the claim from certified herds, for herds fulfilling the welfare requirements above the minimum standards established by law. Thus, animal welfare would have an additional economic value, as it would offer to consumers a product of higher quality, and, at the same, it could become an opportunity to increase farmers' income.

Recent market researches (European Commission, 2012) have highlighted how important is protecting animals for European citizens. This was also revealed in more recent studies (Cenci-Goga and Fermani, 2010; Cenci-Goga et al. (2010), in which $82 \%$ of consumers emphasised the importance of protection of animals, regardless of costs, accepting to pay a higher price for food from animal breeding systems where animal welfare is respected.

Taking into account the market response, the scientific evidence and the advantages in term of hygiene, organoleptic quality and shelf life, in UK in 2015 the religious communities have accepted to introduce stunning in ritual slaughtering. As also suggested in our study, this virtuous model where religion and science meet up and find a balance point should be promoted and replicated in other European countries.

\section{References}

Bondy PK, 1980. The adrenal cortex. In: Bondy PK, Rosemberg LE (eds.) Metabolic control and disease. 8th ed. WB Saunders, Philadelphia, PA, USA. pp. 1427-1500.

Bozzo G, Di Pinto A, Bonerba E, Ceci E, Mottola A, Roma R, Capozza P, Samoilis G, Tantillo G, Celano GV, 2017. Kosher slaughter paradigms: Evaluation of slaughterhouse inspection procedures. Meat Sci 128:30-3.

Cenci-Goga BT, Fermani AG, 2010. La macellazione religiosa. Protezione degli animali e produzione igienica della carne. Point Veterinaire Italie, Milan, Italy.

Cenci-Goga BT, Mattiacci C, De Angelis G, Marini P, Cuccurese A, Rossi R, Catanese B, 2010. Religious slaughter 
in Italy. Vet Res Commun 34(Suppl.1): 139-43.

Cook NJ, Schaefer AL, Lepage P, Jones SM, 1996. Salivary vs. serum cortisol for the assessment of adrenal activity in swine. Can J Anim Sci 76:329-35.

European Commission, 2004. Commission Regulation of 29 April 2004 laying down specific hygiene rules for on the hygiene of foodstuffs, 853/2004/EC. In: Official Journal, L 139/55, 30.4.2004.

European Commission, 2009. Commission Regulation of 24 September 2009 on the protection of animals at the time of killing, 1099/2009/EC. In: Official Journal, L 303/1, 18.11.2009.

European Commission, 2012. European Union strategy for the protection and welfare of animals 2012-2015 COM (2012) 6 final. European Commission, Brussels, Belgium.

Farouk MM, Al-Mazeedi HM, Sabow AB,
Bekhit AED, Adeyemi KD, Sazili AQ, Ghani A, 2014. Halal and kosher slaughtermethods and meatquality: A review. Meat Sci 98:509-14.

Faucitano L, 1998. Preslaughter stressors effects on pork: A review. Muscle Foods 9:293-303.

Greenwood PL, Shutt DA, 1992. Salivary and plasma cortisol as an index of stress in goats. Austral Vet J 69:161-3.

Informatore Zootecnico, 2009. Qualità della carne bovina. Available from: http://www.informatorezootecnico.it/bo vini-da-carne/qualita-della-carne-bovina/

Lensink BJ, Fernandez X, Cozzi G, Florand L, Veissier I, 2001. The influence of farmers' behavior on calves' reactions to transport and quality of veal meat. J Anim Sci 79:642-52.

Önenç A, Kaya A, 2004. The effect of electrical stunning and percussive captive bolt stunning on meat quality of cattle processed by Turkish slaughter procedures. Meat Sci 66:809-15.

Pol F, Courboulay V, Cotte JP, Martrenchar A, Hay M, Mormede P, 2002. Urinary cortisol as an additional tool to assess the welfare of pregnant sows kept in two types of housing. Vet Res 33:13-22.

Shutt DA, Fell LR, 1985. Development of a salivary cortisol method for detecting changes in plasma "free" cortisol arising from acute stress in sheep. Austral Vet J. 62:403-6.

Sjaastad ØV, Sand O, Hove K, 2013. Fisiologia degli animali domestici. Edizione italiana a cura di Carlo Tamanini. Ambrosiana ed., Milan, Italy.

Stewart M, Webster JR, Schaefer AL, Cook NJ, Scott SL, 2005. Infrared thermography as a non-invasive tool to study animal welfare. Anim Welfare 14:319-25. 